\title{
Comunicação
}

[Communication]

\section{Características microbiológicas de amostras de leite de tanque comunitário}

\author{
[Microbiological characteristics of milk samples from community bulk tanks] \\ V. Souza ${ }^{1}$, A. Nader Filho ${ }^{2}$, L.M. Ferreira ${ }^{3}$, N.D. Cereser $^{1}$ \\ ${ }^{1}$ Aluna de pós-graduação - FCAV-UNESP - Jaboticabal, SP \\ ${ }^{2}$ Faculdade de Ciências Agrárias e Veterinárias - UNESP - Jaboticabal, SP \\ ${ }^{3}$ UNICASTELO - Descalvado, SP
}

\begin{abstract}
A pecuária leiteira vem sendo marcada por um intenso processo de modernização, seleção e especialização da produção, com significativas mudanças nos sistemas de armazenamento e transporte, sendo o resfriamento e a granelização do leite tendências irreversíveis na produção (Santos e Fonseca, 2003). A coleta a granel é realizada em caminhões isotérmicos, em dias alternados, e vem substituindo gradativamente a coleta em latões, de modo a modernizar e agilizar a recepção da matéria prima pelas indústrias, gerando economia de mão de obra e transporte, bem como diminuindo as perdas por acidificação do leite. Considerando que, dentro desse novo cenário de modernização da coleta de leite, a palavra-chave é racionalização com otimização do processo, potencialmente as indústrias captadoras de leite optam pelo fechamento ou cancelamento de linhas de leite deficitárias ou que geram baixa eficiência, especialmente aquelas mais distantes das fábricas, ou de difícil acesso para os caminhões e compostas por produtores que apresentam pequena escala de produção (Santos e Fonseca,
\end{abstract} 2003).

No momento em que se discutiu a legislação, observou-se que muitos produtores poderiam abandonar a atividade por não terem condições de ajustarem à nova legislação e também por terem dificuldades em adquirir tanques resfriadores individualmente, devido a seu alto custo. Para evitar esse problema, previu-se na norma, a possibilidade de se resfriar o leite em tanques comunitários (tanques em regime de condomínio), formando associações de produtores, utilizando um único tanque de expansão, o qual é instalado em uma das propriedades e recebe leite de outras. Dessa forma, o investimento fica pulverizado entre vários pequenos produtores, o que viabiliza a permanência deles na atividade e reduz a comercialização do leite informal e a ocorrência do êxodo rural (Ribeiro e Teixeira, 2000).

Diante das poucas informações disponíveis sobre a qualidade do leite produzido neste novo sistema, idealizou-se o presente trabalho com o objetivo de conhecer as características microbiológicas, por meio da determinação da contagem de microrganismos mesófilos e de psicrotróficos, de 72 amostras de leite cru provenientes de nove propriedades rurais situadas na região da Gameleira, município de Sacramento, MG, assim como 12 amostras do leite de conjunto dessas propriedades contido em um tanque comunitário com capacidade para 3.000L.

No momento da entrega, após a realização da prova do alizarol a $74^{\circ} \mathrm{GL}$, eram colhidas amostras individuais diretamente do latão de leite de cada propriedade e também da mistura do leite de todas as propriedades, colhido no tanque comunitário. Decorridas 24 horas, procedia-se a colheita de amostra do leite contido no tanque comunitário, antes que houvesse novo transvase do leite oriundo de cada propriedade. Em seguida, repetia-se o procedimento das colheitas de amostras de leite de cada propriedade e da mistura do leite de todas as propriedades. As

Recebido em 4 de dezembro de 2008

Aceito em 15 de maio de 2009

E-mail: vivianesouzavet@yahoo.com.br 
amostras foram colhidas após constante homogeneização em frascos previamente esterilizados e acondicionadas em caixa isotérmica contendo gelo. Essas foram transportadas para o laboratório onde se realizavam as contagens de microrganismos mesófilos e de psicrotróficos viáveis (Compendium..., 2001).

Das 72 amostras de leite cru analisadas, 66 (91,6\%) apresentaram contagens de mesófilos abaixo de $10^{6} \mathrm{UFC} / \mathrm{mL}$ (Tab. 1), que corresponde ao limite máximo estabelecido pela $\mathrm{IN} \mathrm{n}^{\circ} 51$, enquanto seis $(8,4 \%)$ apresentaram-se acima desse valor, portanto, em desacordo com os padrões legais. A propriedade 1 foi a que apresentou a maior média de produção de litros de leite/dia e as maiores contagens de microrganismos mesófilos, muito embora nela fosse realizada a ordenha mecânica. Acredita-se que os procedimentos usuais de higiene durante a ordenha, limpeza e sanitização dos utensílios e equipamentos dessa propriedade não estivessem sendo praticados adequadamente. A propriedade 8 também utilizava ordenha mecânica, e as contagens médias de microrganismos mesófilos se mantiveram baixas, demonstrando a preocupação do produtor com a higiene da ordenhadeira, assim como a higienização dos utensílios.

Tabela 1. Valores médios* das populações de microrganismos mesófilos e de psicrotróficos das 72 amostras de leite cru provenientes das nove propriedades rurais que entregavam leite no tanque de expansão comunitário em Sacramento, MG

\begin{tabular}{cccc}
\hline Propriedade & $\begin{array}{c}\text { Média da produção diária } \\
\text { (litros de leite) }\end{array}$ & $\begin{array}{c}\text { Microrganismos mesófilos } \\
(\mathrm{UFC} / \mathrm{mL})\end{array}$ & $\begin{array}{c}\text { Microrganismos } \\
\text { psicrotróficos } \\
(\mathrm{UFC} / \mathrm{mL})\end{array}$ \\
\hline 1 & 506 & $1,5 \times 10^{6}$ & $2,0 \times 10^{4}$ \\
2 & 100 & $1,2 \times 10^{4}$ & $4,6 \times 10^{3}$ \\
3 & 115 & $4,2 \times 10^{4}$ & $6,7 \times 10^{3}$ \\
4 & 297 & $8,0 \times 10^{4}$ & $8,8 \times 10^{3}$ \\
5 & 44 & $2,3 \times 10^{4}$ & $3,3 \times 10^{3}$ \\
6 & 90 & $1,8 \times 10^{5}$ & $6,1 \times 10^{3}$ \\
7 & 38 & $1,2 \times 10^{5}$ & $6,4 \times 10^{4}$ \\
8 & 216 & $2,6 \times 10^{4}$ & $1,1 \times 10^{4}$ \\
9 & 78 & $1,2 \times 10^{4}$ & $2,7 \times 10^{3}$ \\
\hline
\end{tabular}

* Média geométrica

Os valores obtidos na contagem de mesófilos das 72 amostras de leite cru variaram de $6,2 \times 10^{2}$ a 2,2 x $10^{7} \mathrm{UFC} / \mathrm{mL}$. Brito et al. (2002), ao acompanharem a qualidade microbiológica do leite produzido por 12 rebanhos leiteiros, localizados em sete municípios da Zona da Mata do Estado de Minas Gerais, observaram médias geométricas das contagens de mesófilos abaixo de $6,5 \times 10^{5} \mathrm{UFC} / \mathrm{mL}$ em nove rebanhos e acima de $1,0 \times 10^{6} \mathrm{UFC} / \mathrm{mL}$ em três. Estes resultados foram mais elevados que os obtidos no presente estudo.

Os valores obtidos na contagem de microrganismos psicrotróficos variaram de $3,2 \times 10^{2}$ a 9,6 x $10^{5} \mathrm{UFC} / \mathrm{mL}$. A propriedade 7 apresentou a maior média geométrica nas contagens de microrganismos psicrotróficos. De certa forma, independentemente da pequena quantidade de leite produzida e do fator diluição ocorrido, o leite dessa propriedade estava contribuindo para depreciar a qualidade do leite de conjunto do tanque comunitário. A presença desses microrganismos bem como o longo tempo de armazenamento do leite favoreceram ainda mais essa condição.

Santos e Bergmann (2003), ao analisarem 125 amostras de leite da região serrana do Estado de Santa Catarina, obtiveram contagens médias de psicrotróficos de $2,1 \times 10^{6} \mathrm{UFC} / \mathrm{mL}$, valor maior que os observados neste trabalho.

Com relação aos valores médios na contagem de mesófilos, das 12 amostras de leite cru de conjunto, $11(91,6 \%)$ apresentaram contagens abaixo de $10^{6} \mathrm{UFC} / \mathrm{mL}$, conforme estabelecido pela IN n $\mathrm{n}^{\mathrm{o}} 51$, enquanto apenas uma $(8,4 \%)$ apresentou-se fora dos referidos padrões (Tab. 2). Tais achados evidenciaram que a qualidade microbiológica do leite, objeto desta investigação, foi muito superior à observada por Brito et al. (2003) na Zona da Mata Mineira. Esses autores verificaram que entre as 335 amostras dos 22 tanques comunitários estudados, apenas 69 $(20 \%)$ apresentaram contagens abaixo de $10^{6}$ $\mathrm{UFC} / \mathrm{mL}$. 
Tabela 2. Valores médios* da população de microrganismos mesófilos e de psicrotróficos das 12 amostras do leite de conjunto das nove propriedades rurais que entregavam leite no tanque de expansão comunitário em Sacramento, MG

\begin{tabular}{cccc}
\hline \multirow{2}{*}{ Momento } & $\begin{array}{c}\text { Volume de leite } \\
\text { armazenado (L) }\end{array}$ & $\begin{array}{c}\text { Microrganismos mesófilos } \\
(\mathrm{UFC} / \mathrm{mL})\end{array}$ & $\begin{array}{c}\text { Microrganismos } \\
\text { psicrotróficos } \\
(\mathrm{UFC} / \mathrm{mL})\end{array}$ \\
\hline 0 & 1.484 & $2,3 \times 10^{5}$ & $3,7 \times 10^{4}$ \\
24 horas & 1.484 & $2,1 \times 10^{5}$ & $2,9 \times 10^{5}$ \\
Remontagem & 2.968 & $3,3 \times 10^{5}$ & $3,8 \times 10^{4}$ \\
\hline
\end{tabular}

* Média geométrica

A média geométrica de todas as contagens de mesófilos obtidas entre as 12 amostras analisadas foi de $1,8 \times 10^{5} \mathrm{UFC} / \mathrm{mL}$. Este achado foi semelhante ao obtido por Ponsano et al. (2004). A qualidade microbiológica do leite testado estava dentro dos limites propostos pela Instrução Normativa $\mathrm{n}^{\circ}$ 51. O fato de o sistema de uso de tanque comunitário ser praticamente familiar, visto que apenas um dos produtores não fazia parte da família, pode ter contribuído para este resultado, já que havia uma relação de confiança entre eles, pois possuíam interesses comuns.

Provavelmente, a elevada ocorrência de amostras com contagens de microrganismos mesófilos abaixo de $10^{6} \mathrm{UFC} / \mathrm{mL}$ deve-se à proximidade existente entre o tanque comunitário e as nove propriedades estudadas. Segundo Brito et al. (2003), esse fato contribui para a rápida entrega do leite de modo a controlar a multiplicação microbiana, principalmente nos meses mais quentes do ano.

A média geométrica de microrganismos psicrotróficos obtidas das 12 amostras de leite cru de conjunto foi de $7,4 \times 10^{4} \mathrm{UFC} / \mathrm{mL}$. Este valor foi inferior ao obtido por Brito et al. (2003) que observaram que, entre os 22 tanques comunitários por eles estudados, o que apresentou melhor qualidade microbiológica para microrganismos psicrotróficos, registrou média geométrica de $1,0 \times 10^{5} \mathrm{UFC} / \mathrm{mL}$.

Os resultados permitiram concluir que o uso de tanque comunitário pode proporcionar a obtenção de leite com qualidade microbiológica satisfatória, atendendo aos limites propostos pela legislação vigente, desde que obedecidas as normas de boas práticas de produção.

Palavras-chave: leite cru, tanque comunitário, microrganismos mesófilos, microrganismos psicrotróficos

\begin{abstract}
Microbiological quality of 72 samples of raw milk taken from nine cattle-rearing farms and from 12 samples of milk from a community bulk tank shared by the same farms in Gameleira region, municipality of Sacramento, MG, were evaluated. Mesophilic and psychrotrophic microorganisms were counted. Mesophilic and psychrotrophic microorganisms counts of the 72 raw milk samples from nine farms ranged from $6.2 \times 10^{2}$ to $2.2 \times 10^{7} \mathrm{CFU} / \mathrm{mL}$ and from $3.2 \times 10^{2}$ to $9.6 \times 10^{5} \mathrm{CFU} / \mathrm{mL}$, respectively. Geometric means of all counts of mesophilic and psychrotrophic microorganisms from the 12 raw milk samples from the community bulk tank of nine farms were $1.8 \times 10^{5} \mathrm{CFU} / \mathrm{mL}$ and $7.4 \times 10^{4} \mathrm{CFU} / \mathrm{mL}$, respectively. Results showed that community bulk tank may be a great asset for obtaining satisfactory microbiological quality milk.
\end{abstract}

Keywords: raw milk, community bulk milk tank, mesophilic microorganisms, psychrotrophic microorganisms

\title{
AGRADECIMENTOS
}

À FAPESP - Fundação de Amparo à Pesquisa do Estado de São Paulo, pelo auxílio financeiro. Processo $n^{\circ} 04 / 12511-0$. 


\section{REFERÊNCIAS BIBLIOGRÁFICAS}

BRITO, M.A.V.P.; BRITO, J.R.F.; PORTUGAL, J.A.B. Identificação de contaminantes bacterianos no leite cru de tanques de refrigeração. In: CONGRESSO NACIONAL DE LATICÍNIOS, 19., 2002, Juiz de Fora. Anais... Juiz de Fora: Templo, 2002. p.83-88.

BRITO, M.A.V.P.; PORTUGAL, J.A.B. DINIZ, F.H; et al. Qualidade do leite armazenado em tanques de refrigeração comunitários. In: MARTINS, C.E.; FONSECA, P.C.; BERNARDO, W.F. et al. (Eds). Alternativas tecnológicas, processuais e de políticas públicas para a produção de leite em bases sustentáveis. Juiz de Fora: Embrapa Gado de Leite, 2003. p.21-34.

COMPENDIUM of methods for the microbiological examination of foods. 3.ed. Washington: APHA, Committee on Microbiological Methods for Foods, 2001. 1219p.
PONSANO, E.H.G.; PINTO, M.F.; POLÔNIO, A.L.C. et al. Adequação do leite produzido na região de Araçatuba aos padrões preconizados pela IN 51/2002 - MAPA. Parte 2 - Leite individual. In: CONGRESSO BRASILEIRO DE QUALIDADE DO LEITE, 1., 2004, Passo Fundo. Anais eletrônico... Passo Fundo, CBQL, 2004. (CD-ROM).

RIBEIRO, M.T.; TEIXEIRA, S.R.L Qualidade do leite em tanques de expansão individuais ou comunitários. Glória Rural, v.3, p.28-35, 2000.

SANTOS, D.; BERGMANN, G.P. Influência da temperatura durante o transporte, sobre a qualidade microbiológica do leite cru. III Psicrotróficos. Hig. Alim., v.17, p.86-91, 2003.

SANTOS, M.V.; FONSECA, L.F.L. Granelização e resfriamento do leite e seu impacto sobre a qualidade. Leite Derivados, n.71, p.35-44, 2003. 